\title{
Identification of Internal Residual Stress in the Weld and Heat Affected Zone
}

\author{
$1^{\text {st }}$ Dusan Mital ${ }^{1}, 2^{\text {nd }}$ Peter Michalik ${ }^{2}, 3^{\text {rd }}$ Frantisek Botko ${ }^{3}, 4^{\text {th }}$ Andrej Czan ${ }^{4}, 5^{\text {th }}$ Jozef $^{\text {An }}$ \\ Nosal $^{5,} 6^{\text {th }}$ Vitalii Kolesnyk ${ }^{6}, 7^{\text {th }}$ Marta Harnicarova $^{7}$ \\ \{dusan.mital@tuke.sk ${ }^{1}$, peter.michalik@tuke.sk ${ }^{2},{ }^{3}$ frantisek.botko@tuke.sk\}
}

Technical University of Kosice, Faculty of Manufacturing Technologies with a seat in Presov, Sturova 31, 08001 Presov, Slovakia ${ }^{1,2,3}$

\begin{abstract}
Presented article is focused on monitoring residual stress in heat affected zone created during the process of welding. Measuring was realized by using RTG diffraction method such a nondestructive method (NDT). Experimental material used for testing was construction steel S235 and welding method MIG. RTG diffractometer used for evaluation of residual stress values was Proto XRD, where was created dependence of residual stress on welding current and also on length from welded join.
\end{abstract}

Keywords: residual stress, welded join, RTG diffraction, heat affected zone

\section{Introduction}

Residual stresses or internal stresses are stresses in the internal parts of materials, which do not disappear even after interrupt the forces or load of material, which are close connected with plastic deformation. In the fact of this is influenced function of machined surface. Deformation can be also caused by heating in the zone of machining, when are formed phase stresses. Formations of phase stresses have the effect of change material density. If the density of material is increased compared to the material without stresses, stress will be caused by tensile stress (+). If the density is reduced, stress will be caused by compression stress.

Tensile stresses occur in subsurface of material by stretching grains, which has the effect to reduce product life and deterioration of mechanical properties. In the case of compression stress grains are pressured and changing their geometry, what causes their rigidity and better mechanical properties (life of product).

Residual stress can be divided into three general groups (classes):

1. macroscopic stresses created by the machining of material, by forming the material, and so on,

2. stresses including to this group are in grains and crystals of small quantities. Stress is subjected to the anisotropy of grains. They are homogeneity in small areas of polycrystals. Stresses of this group have not to affect macro geometry of material,

3. stress in third group appears in distances between atoms, they are in-homogeneous in whole volume of the material. Stresses of this group do not change microscopy structure of the material.

In materials tensile stress appears as a positive and compressive stress as a negative. Residual stresses are influenced by three factors:

- plastic deformation, 
- phase transition,

- local thermal heating.

Thermal heating is closely related to the machining and stress created in the area of machining is shown on next Figure 1 [1-6].

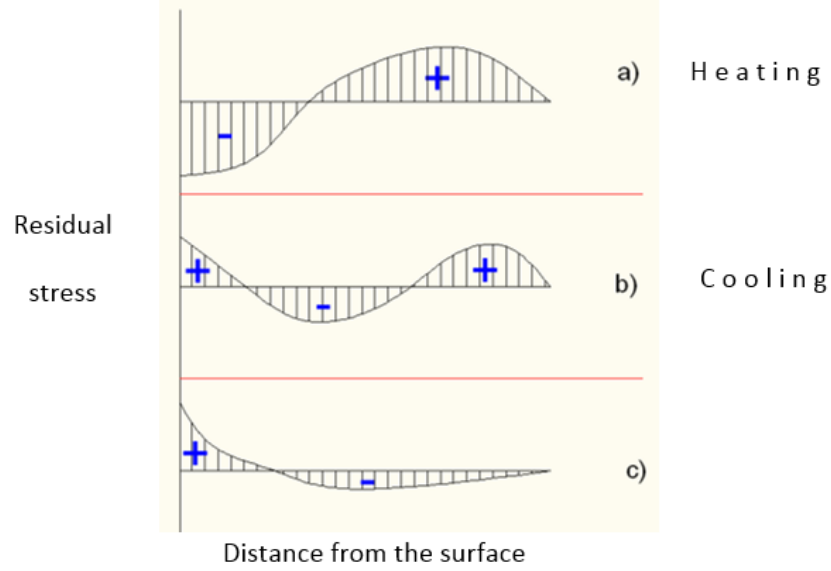

Fig. 1. Created stress after machining [1]

Measuring residual stress by using roentgen diffraction is based on deformation of crystal lattice and corresponding elastic constant, where is expected linearity of elasticity deformation in the crystallographic planes. A method is based on fundamental interaction between photon $\mathrm{X}$ - ray and crystal lattice. Geometrical conditions of diffraction in the case of three dimensional periodical structures are determined by Laue's diffraction conditions. Alternatively choice to de-terminate diffraction is to use Bragg's law (Figure 2), which is based on conception of crystal planes. Bragg's law is expressed from interference conditions from optic law - trajectory of two rays is an integer multiple of wavelength (1). Incidence angle $\theta$ is measured from diffracting planes, where interference condition is satisfied is called Bragg's law $[1,5]$.

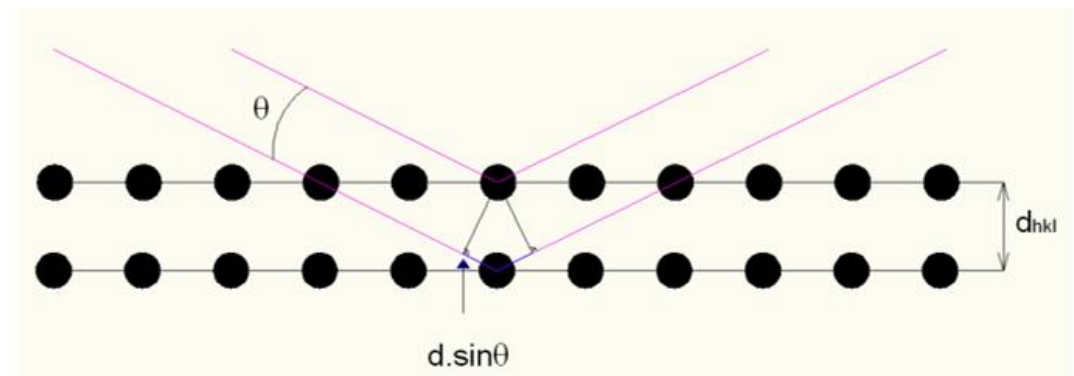

Fig. 2. Bragg's law angle $[1,5]$

$\lambda=2 . d \cdot \sin 2$

Where: $\quad \lambda$-wavelength of primary radiations

(1)

$d$ - distance between atoms

2 - Bragg's angle 


\section{Experimental specification}

Tested material used for experiment was construction steel S235 (suitable for stressed product made by molding, sheets metals, screws, rivets and so on). Mechanical properties are shown in Table 1 and delivered semi product had dimensions 180 x 70 x $1100 \mathrm{~mm}$.

Table 1. Mechanical properties of experimental material (HT = Heat Treatment)

\begin{tabular}{cccc}
\hline Material & Properties, & \multicolumn{2}{c}{ Mechanical properties } \\
according & HT & & \\
EN ISO & & & \\
\hline $\begin{array}{c}\text { S235 } \\
(\mathbf{C = 0 , 2 2} \%)\end{array}$ & $\begin{array}{c}\text { Structural steel, } \\
\text { unsupported, } \\
\text { weldability } \\
\text { guaranteed }\end{array}$ & $R e=200-240 \mathrm{MPa}$ & $\sigma D t$ (static) $=100-150 \mathrm{MPa}$ \\
& & $R m=340-420 \mathrm{MPa}$ & $\sigma D t$ (disappearing) $=70-100 \mathrm{MPa}$ \\
& & &
\end{tabular}

\subsection{Applied technology of machining and welding process}

Firstly had to be material cut into plates with thickness $20 \mathrm{~mm}$ (12 samples, which were welded -6 final samples). Subsequently the process of preparing consist of milling the edges by $2 \times 60^{\circ}$ (milling center CNC Pinnacle VMC 650S). Technology of welding used in experiment was with PA approach by MIG welding semiautomatic device ForMIG 669FW (suitable for technologies MIG and MAG designed for heavy industry with built in water cooling) - Figure 3.
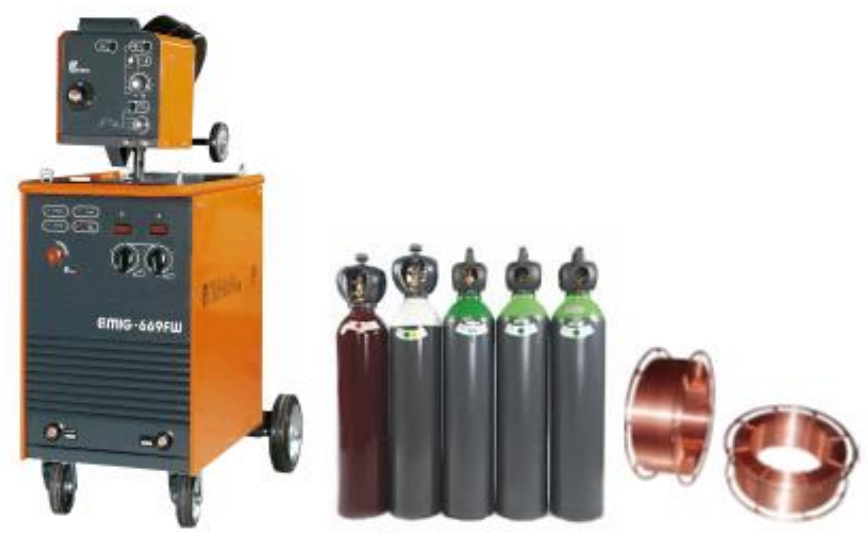

Fig. 3. Welding semiautomatic device ForMIG 699 FW, Gas Cylinders EUROMIX M21, welding wire ESAB Weld G3Si1 [7-9].

Welding gas used in experiment was Euromix M21 (mixture of 21\% Carbon dioxidespecially designed for welding processes with active gas Ar and can be used at arc welding, welding of carbon and stainless steels) (Table 2). Provides high weld quality high level of penetration with minimal spraying and low values of vapors. Applied welding material ESAB 
Weld G3Si1 s diameter $1.2 \mathrm{~mm}$ is designated to welding unalloyed and low alloyed steels with $\mathrm{C}$ and is suitable for tee and butt joins.

Table 2. Welding parameters used in the experiment

\begin{tabular}{lcccccc}
\hline $\begin{array}{c}\text { Diameter } \\
(\mathbf{m m})\end{array}$ & $\begin{array}{c}\text { Current } \\
(\mathbf{A})\end{array}$ & $\begin{array}{c}\text { Voltage } \\
(\mathbf{V})\end{array}$ & $\begin{array}{c}\text { Welding } \\
\text { metal yield }\end{array}$ & $\begin{array}{c}\text { Gas } \\
\text { consumption }\end{array}$ & $\begin{array}{c}\text { Feeding } \\
\text { speed }\end{array}$ & $\begin{array}{c}\text { Welding } \\
\text { Performance }\end{array}$ \\
\hline $\mathbf{0 , 8}$ & $60-200$ & $18-24$ & 95 & 14 & $3.2-13$ & $0.8-3.0$ \\
\hline $\mathbf{1 , 0}$ & $80-300$ & $18-32$ & 95 & 14 & $2.7-15$ & $1.0-5.6$ \\
\hline $\mathbf{1 , 2}$ & $120-380$ & $18-34$ & 95 & 14 & $2.7-15$ & $1.3-8.0$ \\
\hline
\end{tabular}

Experiment was realized for several welding parameters: welding current, gas flow, feeding speed of the wire, and covers layers (Figure 4), (Table 3). Method of measuring residual stress was realized by using device RTG diffractometer PROTO XRD with CNC table (Figure 5).
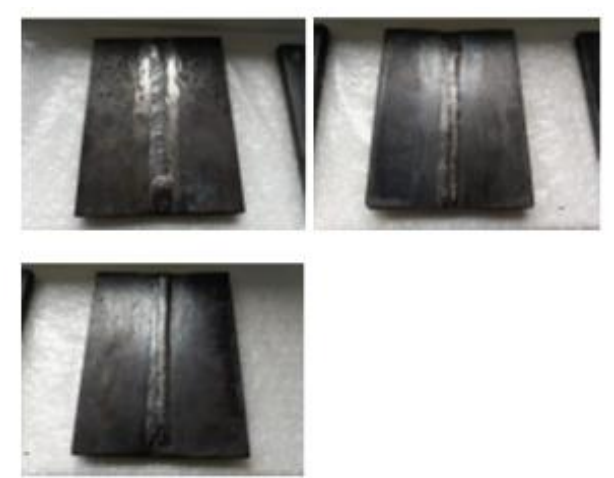

Fig. 4. Welded samples 1, 2 and 3

Table 3. Welding parameters for samples

\begin{tabular}{cccc}
\hline & Sample n. 1 & Sample n. 2 & Sample n. 3 \\
\hline Gas flow L/ min. & 10 & 11 & 11 \\
\hline Feeding speed m/ min. & 5 & 6 & 7 \\
\hline Root of weld & $140 \mathrm{~A}-17 \mathrm{~V}$ & $150 \mathrm{~A}-18 \mathrm{~V}$ & $160 \mathrm{~A}-19 \mathrm{~V}$ \\
\hline Cover layers & $180 \mathrm{~A}-19 \mathrm{~V}$ & $190 \mathrm{~A}-20 \mathrm{~V}$ & $200 \mathrm{~A}-20 \mathrm{~V}$ \\
\hline
\end{tabular}

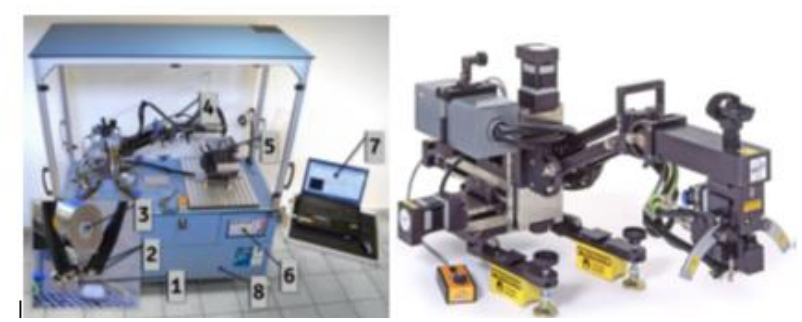

Fig. 5. Measuring system PROTO XRD - RTG diffractometer

1 - X-ray collimator ; 2 - a pair of deflectors capturing diffractive cone; 3 - X-ray tube with Cr target; 4 - Cobralink ${ }^{\circledR}$ flexible measuring arm; $5 \mathrm{CNC}$ and rotary table; 6 - control unit; 7 - PC s software; 8 iXRDlaboratory cabinet [10]. 
Procedure of measuring -

1. Fix the measuring products (surface perpendicularly to measuring head and collimator.

2. Set the measuring height of the measuring head (focusing) - RTG ray penetration is $12 \mu \mathrm{m}$, what represent surface and subsurface layer- RTG ray diffract in the shape of diffraction cone depending on residual stress character (compressive and tensile) and subsequently is captured by deflectors. Gradually is X-ray transmitted in variant angles from the range from $+30^{\circ}$ to $-30^{\circ}$.

3. Signals from detector and evaluated by analytical software XrdWin and are written to Gaussian distribution. The grain size is evaluated as curves width, when wider gaps between curves represent finer structure of the material and vice versa for narrower gaps between curves describe material with bigger grains. RTG ray is reflected with different intensity from grains what is transformed into gauss distribution by method FWHM (full width at half maximum).

Measuring system with automatic positioning table controlled by CNC system provides possibility to map surface in $2 \mathrm{D}$ respectively in $3 \mathrm{D}$.

\section{Results of experiment and discussion}

Results values of RTG diffraction for sample 1 (Table 4) represent increasing the values of residual stress with heated affected zone. Points 1 and 5 were set out of heat affected zone in raw material and values of residual stress in that point was near to 0MPa. Points 2 and 4 were oriented into heat affected zone, where is evident increase of residua tensile stress values and value 3 was measured in the weld, where values of tensile residual stress acquire the highest values.

Table 4. Measured values of residual stress for sample 1

\begin{tabular}{ccccc}
\hline Points & $\mathbf{X}$ pos & $\mathbf{Y}$ pos & $\mathbf{Z}$ pos & Residual stress \\
\hline $\mathbf{1}$ & 0 & 0 & 0 & 0 \\
\hline $\mathbf{2}$ & 0 & -20 & 0.46 & $-338.3 \pm 20.8$ \\
\hline $\mathbf{3}$ & 0 & -35 & 0.19 & $-189.8 \pm 30.2$ \\
\hline $\mathbf{4}$ & 0 & -50 & 0.74 & $-284.1 \pm 17.1$ \\
\hline $\mathbf{5}$ & 0 & -70 & 0.48 & $45 \pm 98.2$ \\
\hline
\end{tabular}

Results of the experimental sample number 2 represent course of residual stress in the weld and heat affected zone. Using higher welding current cause higher values of residual stress and also the wider heat affected zone, where occurs grain deformation. Measured values of residual stress often causes material deformation, what directly affect the time life of the products and also the geometrical dimensions. Measuring points were set for each experimental case in the same dimension to achieve possibility the comparison of individual values (Table 5).

Table 5. Measured values of residual stress for sample 2

\begin{tabular}{ccccc}
\hline Points & $\mathbf{X}$ pos & Y pos & $\mathbf{Z}$ pos & Residual stress \\
\hline $\mathbf{1}$ & 0 & 0 & 0 & $-109.5 \pm 10.3$ \\
\hline $\mathbf{2}$ & 0 & -25 & 0.92 & $-200.8 \pm 6.6$ \\
\hline $\mathbf{3}$ & 0 & -35 & 0.39 & $-189.8 \pm 29.4$ \\
\hline $\mathbf{4}$ & 0 & -45 & 1.3 & $-196.5 \pm 19.1$ \\
\hline $\mathbf{5}$ & 0 & -70 & 0.61 & $41.3 \pm 5.7$ \\
\hline
\end{tabular}


Results of the experimental sample number 3 were monitored different characters of residual stress composition in comparison with previous evaluated samples. In the case of the experimental sample number 3 were in point 2 and 4 were measured lower values of residual stress than in weld, what represent that heat distribution was not evenly distributed in the material and the highest concentration was composed in the weld area, but by long term influence of heat to material is obviously wider heat affected zone (Table 6).

Table 6. Measured values of residual stress for sample 3

\begin{tabular}{ccccc}
\hline Points & $\mathbf{X}$ pos & Y pos & $\mathbf{Z}$ pos & Residual stress \\
\hline $\mathbf{1}$ & 0 & 0 & 0 & $-41.6 \pm 5.7$ \\
\hline $\mathbf{2}$ & 0 & -25 & 1.16 & $-235.5 \pm 5$ \\
\hline $\mathbf{3}$ & 0 & -35 & 0.15 & $-239.7 \pm 17.7$ \\
\hline $\mathbf{4}$ & 0 & -45 & 1.41 & $-196 \pm 20.8$ \\
\hline $\mathbf{5}$ & 0 & -70 & 0.52 & $-78.3 \pm 4.6$ \\
\hline
\end{tabular}

Residual stress varies depending on heat affected zone. Heat distribution causes recrystallization of grains and deformation, what changes diffraction layers and occurrence of internal residual stress. Minimal values in experimental samples was monitored for sample 1 in raw material on value near to $0 \mathrm{MPa}$, for sample $2-41.3 \mathrm{MPa}$ and for sample 3 also in raw material with residual stress value -41.6 MPa. Maximal values of residual stress in experimental samples were obtained in heat affected zone for sample 1 on value $-338.3 \mathrm{MPa}$, for sample 2 value $-200.8 \mathrm{MPa}$ and for sample 3 was measured value $-239.7 \mathrm{MPa}$ in weld. Subsequent evaluation was based on average values for each measuring area and used for regress analyzing and creation the mathematical prescription of internal residual stress in the process of welding for selected material and technological process (Figure 6).

Graphical dependence of residual stress on length

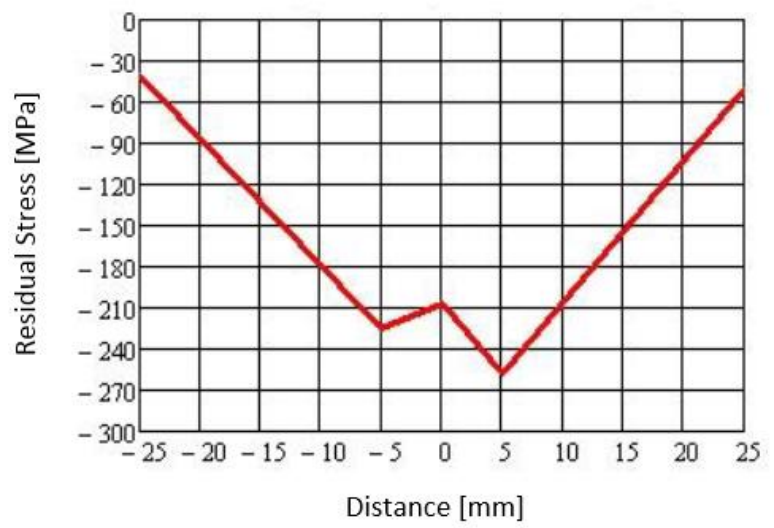

Fig. 6. Graphical dependence of residual stress on length 
Regress function was calculated by using software Mathcad as a dependence of welding current and distance from the weld (Fig. 7), where null position represent welding root. Following Table 7 shows basic statistical characters (Tab. 7).

$$
\sigma=51,152 . I^{\wedge} 2-301,548 . l-185
$$

Where:

$$
\begin{aligned}
& \sigma \text { - residual stress }[\mathrm{MPa}] \\
& I-\text { welding current }- \text { covering layer }[\mathrm{A}] \\
& l-\text { distance from the weld }[\mathrm{mm}]
\end{aligned}
$$

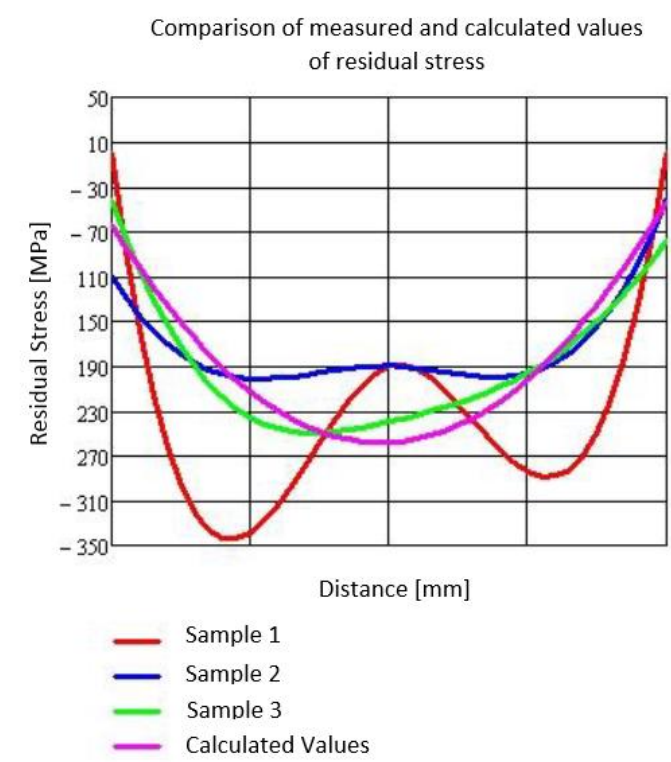

Fig. 7. Comparison of measured and calculated values of residual stress

Table 7.Table of statistical characters

\begin{tabular}{cccc}
\hline Variance & & Standard deviation & Correlation index \\
\hline Sample 1 & $6.848 \times 10^{3}$ & 82.756 & $52.8 \%$ \\
\hline Sample 2 & $1.427 \times 10^{3}$ & 37.779 & $87.3 \%$ \\
\hline Sample 3 & $3.193 \times 10^{3}$ & 56.505 & $96.3 \%$ \\
\hline Calculation & $4.136 \times 10^{3}$ & 64.31 & \\
\hline
\end{tabular}

\section{Conclusion}

Results obtained from the X-ray diffraction, it is clear that the residual stress was varied in each sample, especially in the heat-affected area. The reason was the value of welding current that was used to weld individual samples. For sample 1, the welding current was $180 \mathrm{~A}$, sample 2 was $190 \mathrm{~A}$, and a welding current of up to $200 \mathrm{~A}$ was used in the third sample. When comparing 
the first and third experimental samples, it was clearly seen that the residual stress increased in the third measured sample at the weld point and the main reason was the increased welding current. Increasing the welding current causes increase the residual stress values, which spread into the heat-affected zone, causing the grain to deform and damage the material. In the raw material of samples, the residual stress was equal to zero. Samples 2 and 3 were welded with higher values of current and the primary welding temperature was so high that it could also affect the base material. Mostly all measured points, in each sample had a tensile stress characterization. The maximum stress was measured in a heat-affected area of $-338.3 \mathrm{MPa}$ and at least in the base material where its value was $-41.3 \mathrm{MPa}$. As a result, it has been a tensile stress that adversely affects the material and reduces its mechanical properties.

\section{Acknowledgement}

This research has been elaborated in the framework of the project VEGA 1/0682/17.

\section{References}

[1] Seyedali, S., et al.: Using ultrasonic waves and finite element method to evaluate through-thickness residual stresses distribution in the friction stir welding of aluminum plates. Ma-terials and design. pp. 27-34 (2014).

[2] Pekelnik, J., Kisin, M.: An investigation of material structure transformation in cutting process. Annals of CIRP. Vol. 47/1, pp. 3-68 (1998).

[3] Šomšáková, Z., Zajac, J., Michalik, P., Kasina, M.: Machining of wood plastic composite (pilot experiement). Materiale Plastice. Vol. 49, pp. 55-57 (2012).

[4] Hatala, M., et al.: Balance equation-an essential element of the definition of the drying pocess. Advanced Materials Resesarch. Vol. 849, pp. 310-315 (2014).

[5] Totten, G.: Handbook on residual stress. Bethel: SEM, 417 pages (2005).

[6] Kopec, B., et al.: Non destructive testing of material and constructions. Brno, 384 pages (2008).

[7] http://www.micromega.sk/fm669f.html, 05.05.2017

[8] http://www.trasko.cz/technicke-plyny/, 05.05.2017

[9] http://www.zvarmat.sk/zvaraci-drot-esab-weld-g3si1, 06.07.2017

[10] http://www.protoxrd.com/ixrd-portable.html, 06.07.2017 